\title{
REJUVENATION OF WROUGHT IN-718 DIFFUSER CASES
}

\author{
J. Benson*, R. Hunziker* and C. Williams\# \\ *Division of Materials Science and Technology, CSIR \\ P O Box 395, Pretoria 0001, South Africa \\ \#South African Airways, Jan Smuts Airport 1627, Johannesburg, South Africa
}

\begin{abstract}
$\underline{\text { Abstract }}$
Diffuser cases for certain civilian jet engines are manufactured from the nickel-based superalloy IN-718 in the wrought condition. Over a period of time in service, cracks develop in the outer rear rail which are then repaired by welding in accordance with the manufacturers specification. However these repair cycles were found to increase the frequency of cracking with the eventual result of premature removal of cases from service. The embrittlement has been attributed to excessive $\delta$-phase formation which was due to the solution temperature, employed in the manufacturers repair specification, being below the $\delta$ phase solution temperature. An alternative heat treatment procedure was used to reduce the level of the $\delta$-phase precipitation and this successfully improved the ductility of the metal. This method offers a potential solution to the "ageing IN-718" problem with resultant extended service life-times for these components.
\end{abstract}

Superalloys 1992

Edited by S.D. Antolovich, R.W. Stusrud, R.A. MacKay,

D.L. Anton, T. Khan, R.D. Kissinger, D.L. Klarstrom

The Minerals, Metals \& Materials Society, 1992 


\section{$\underline{\text { Introduction }}$}

Diffuser cases for certain civilian jet engines are manufactured from the nickel-based superalloy IN-718 in the wrought condition. Over a period of time in service, cracks develop in the outer rear rail which are then repaired by welding in accordance with the manufacturers specification. However after several repair cycles a noticeable increase in the frequency and number of cracks has been observed which eventually result in the premature retirement of cases from service. Figure 1 shows an example of a crack in a scrapped diffuser case.

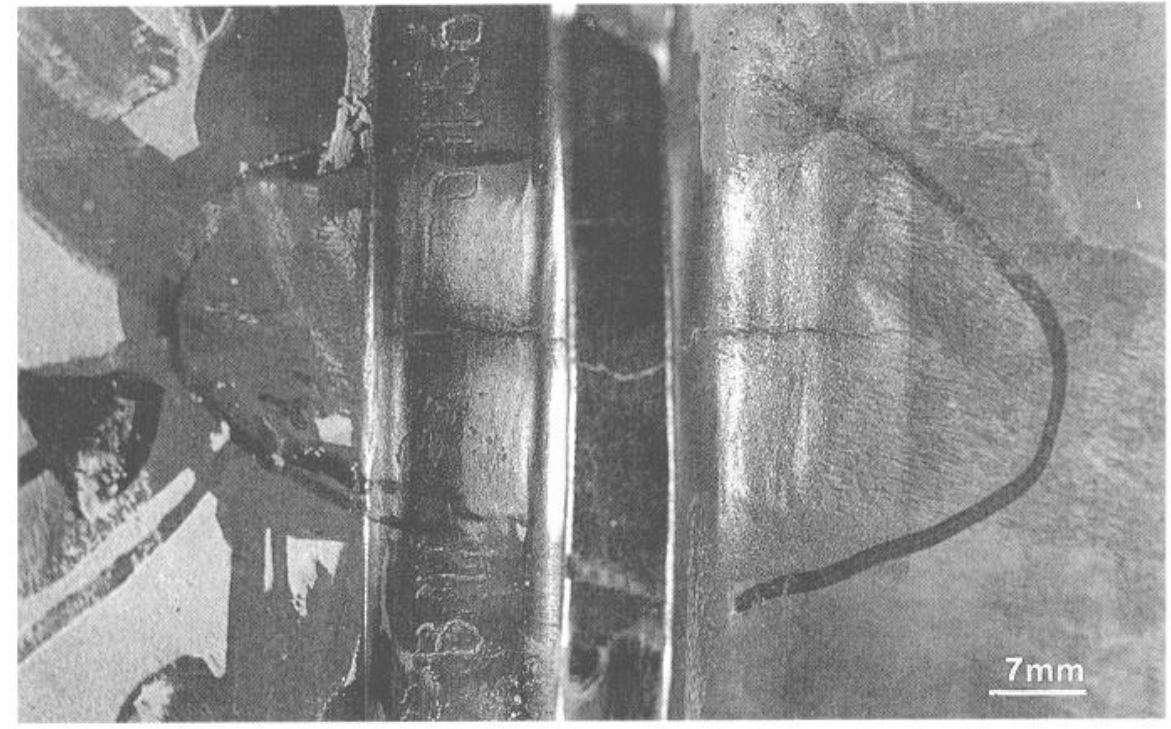

Figure 1 - Typical crack observed in embrittled diffuser cases.

The work done by Mills (1) showed that long term exposure of conventionally heat treated IN-718 to typical operating temperatures can result in the embrittlement of the material due to excess $\delta$-phase formation. The solution temperature of $954-963{ }^{\circ} \mathrm{C}$ employed in the manufacturers weld repair specification would not be effective in reducing the amount of $\delta$ phase as this has a solution temperature of approximately $980{ }^{\circ} \mathrm{C}$. In addition, Koul et al. (2) have reported that a temperature of $955{ }^{\circ} \mathrm{C}$ was found to have promoted the formation of $\delta$-phase. Thus, the use of the recommended solution temperature range would appear to be detrimental to the toughness of the component and thereby shorten its usable lifetime.

The use of a higher solution temperature to dissolve the $\delta$-phase would therefore be indicated as a possible means to "rejuvenate" the material.

At the last Seven Springs Conference, Koul et al. (2) discussed the development of an alternative heat treatment to optimize IN-718 turbine disc microstructures without degrading the low cycle fatigue life of the material. They selected a solution temperature high enough to remove the $\delta, \gamma^{\prime}$ and $\gamma^{\prime \prime}$ phases but without causing excessive grain growth. However complete removal of the $\delta$-phase has been shown to result in notch embrittlement under stress-rupture conditions (3) and so additional post-solution treatments were employed to reform the $\delta$-phase in a controlled manner as well as optimise the $\gamma^{\prime}$ and $\gamma^{\prime \prime}$ precipitates.

The purpose of this study was to apply this modified heat treatment to embrittled IN-718 material and to determine its effectiveness in "renewing" the microstructure and thereby improving the mechanical properties. 


\section{Experimental Procedure}

An embrittled IN-718 diffuser case, retired from service, was used for this exercise and a comparison was made between the metal in this as-received condition and after the following modified heat treatment which was devised by Koul et al. (2).

Table 1 Modified heat treatment (2)

1. Solution treat at $1032{ }^{\circ} \mathrm{C}$ for one hour. Furnace cool to $843{ }^{\circ} \mathrm{C}$ and age at $843{ }^{\circ} \mathrm{C}$ for four hours.

2. Partial solution treat at $926{ }^{\circ} \mathrm{C}$ for one hour. Air cool to room temperature.

3. Age at $718{ }^{\circ} \mathrm{C}$ for eight hours. Furnace cool to $621{ }^{\circ} \mathrm{C}$ and age at $621{ }^{\circ} \mathrm{C}$ for eight hours. Air cool to room temperature

The heat treatment was conducted in a vacuum furnace. Tensile tests were carried out on an Instron servo-hydraulic test rig at room temperature and at $650{ }^{\circ} \mathrm{C}$ at a strain rate of 0.005 per minute. The test specimens were machined from the scrapped diffuser case and were of non-standard dimensions (gauge length $=18.0 \mathrm{~mm}$ and gauge diameter $-3.0 \mathrm{~mm}$ ). Charpy dynamic impact tests were also performed, at room temperature, on blunt notched specimens machined from the embrittled case $[50.0 \mathrm{~mm}(\ell) \times 10.00 \mathrm{~mm}(\mathrm{~h}) \times 7.0 \mathrm{~mm}(\mathrm{w})$; notch radius $=0.25 \mathrm{~mm}$ and notch depth $=3.0 \mathrm{~mm}$.

Specimens for metallography were prepared using standard procedures and the etching to reveal the microstructure was done electrolytically using a $10 \%$ oxalic acid in distilled water solution at $3 \mathrm{~V}$ for approximately 1 second.

\section{$\underline{\text { Results }}$}

Metallographic examination of the embrittled diffuser case metal confirmed that there was a high concentration of the needle-like $\delta$-phase (Figure 2). This however was not uniformly distributed but appeared mainly in regions adjacent to the carbide particles as well as along grain boundaries.

After the modified heat treatment cycle there was a significant reduction in the amounts of $\delta$-phase present (Figure 3). The distribution in this case was more uniform with precipitation occurring mainly along the grain boundaries. No changes to the carbides were noticeable. The very fine sizes of the $\gamma^{\prime}$ and $\gamma^{\prime \prime}$ particles prevented resolution in the scanning electron microscope.

To confirm the detrimental effect of the recommended $954-963{ }^{\circ} \mathrm{C}$ weld repair solution temperature on $\delta$-phase formation, samples of the embrittled IN-718 material were solution treated at $1032{ }^{\circ} \mathrm{C}$ and gas quenched to remove all of the $\delta$-phase. These samples were then heated to $955^{\circ} \mathrm{C}$ for 1 hour and gas quenched and then microstructurally examined for $\delta$. This cycle was repeated eight times. After one cycle, formation of the phase was observed and the concentration of $\delta$ increased with further cycles as shown in Figure 4 . This would explain the gradual onset of embrittlement that had been observed. 


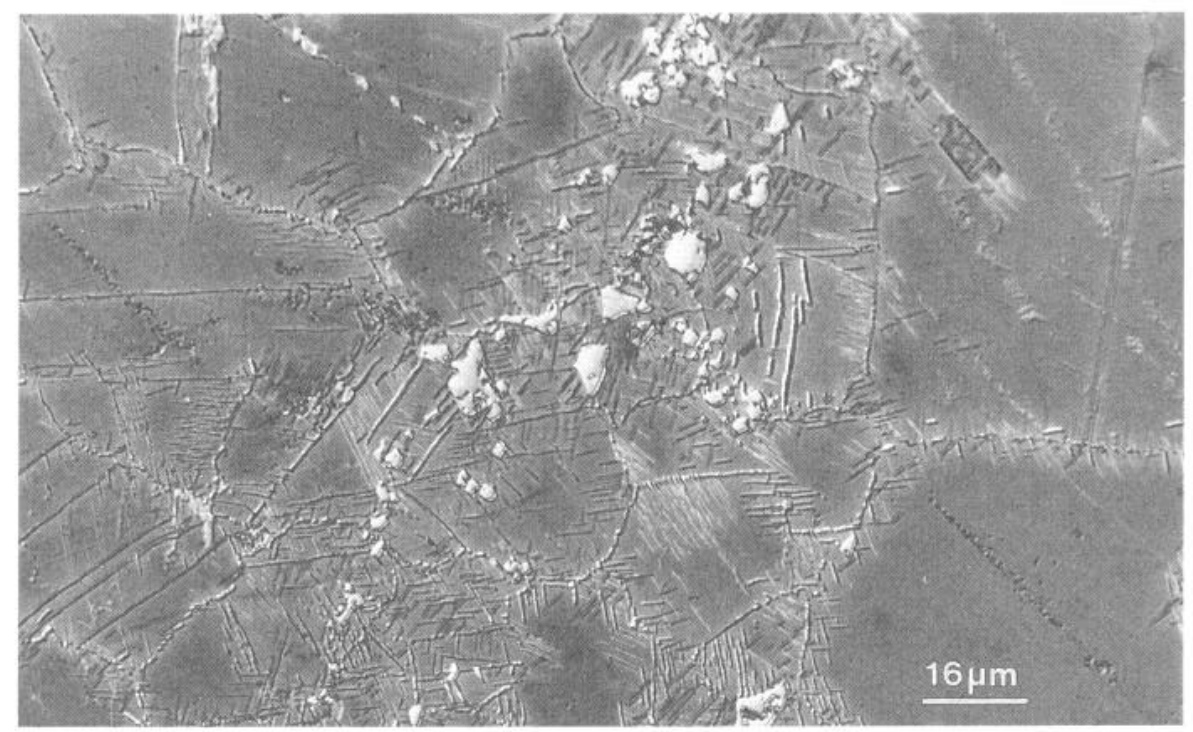

Figure 2 - High $\delta$-phase concentration in embrittled IN-718 diffuser case material.

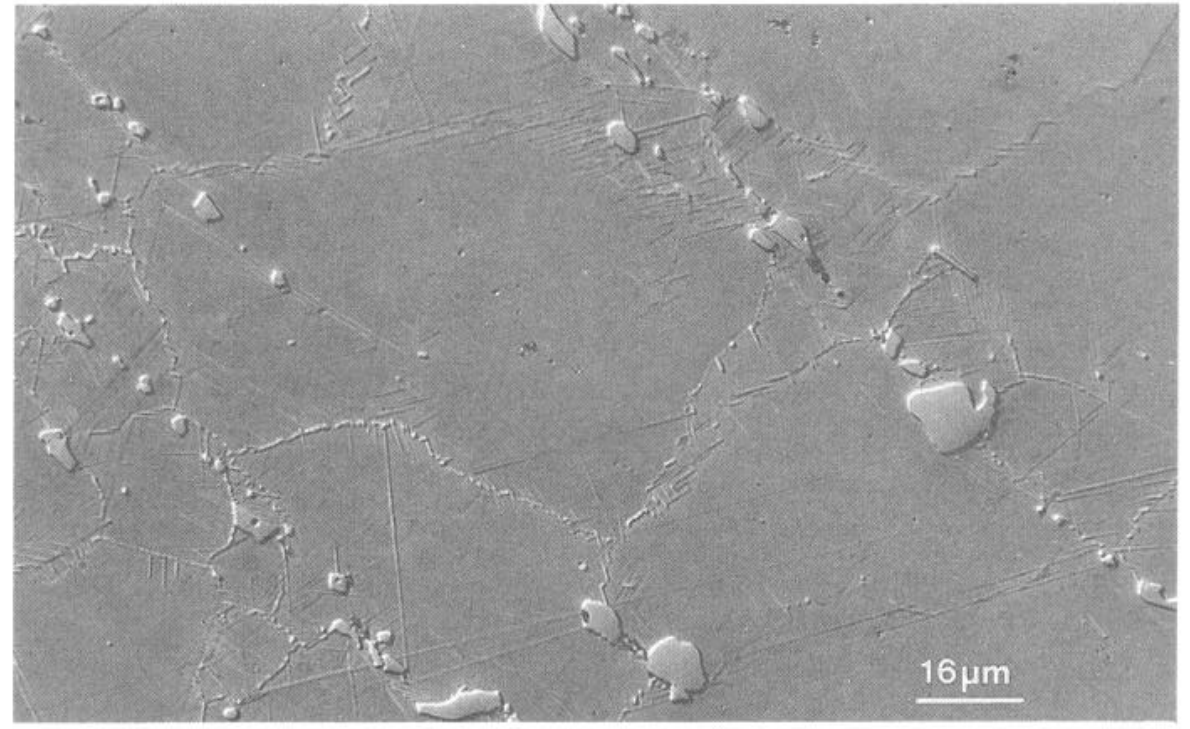

Figure 3 - $\quad$ Significant reduction in the $\delta$-phase concentration after the modified heat treatment. 


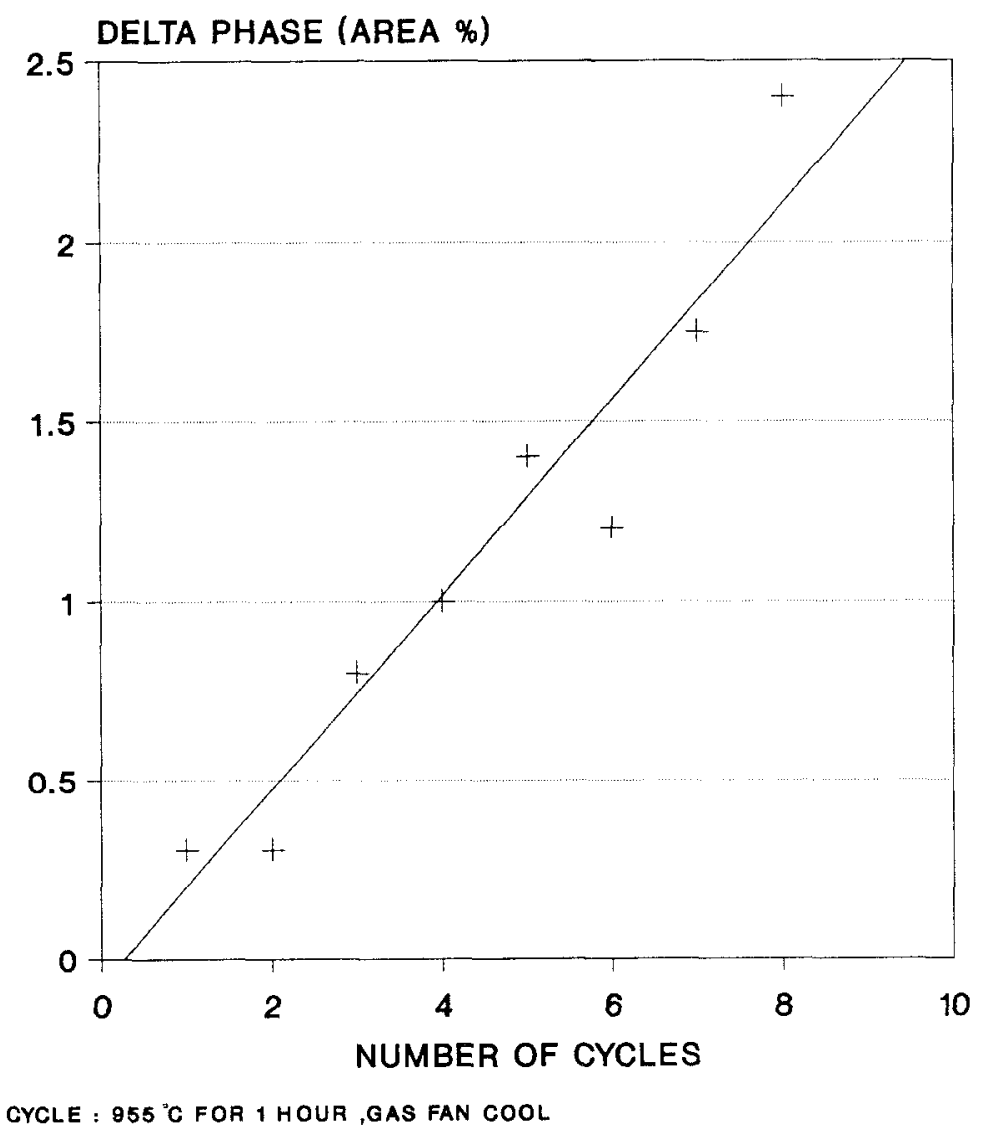

Figure 4 - Effect of repeated use of the standard solution heat treatment temperature of $955^{\circ} \mathrm{C}$ for 1 hour on the $\delta$-phase concentration.

The results of the tensile tests are recorded in Table 2 . The changes in the yield strength and the ultimate tensile strength before and after heat treatment are minor at both room temperature and at $650{ }^{\circ} \mathrm{C}$, however what is noticeable is the significant improvement in both reduction in area and elongation to fracture.

Table 2 Tensile test results

\begin{tabular}{lccccc}
\hline Condition & $\begin{array}{c}\text { Temp. } \\
\left({ }^{\circ} \mathrm{C}\right)\end{array}$ & $\begin{array}{c}0.2 \% \text { Y.S. } \\
(\mathrm{MPa})\end{array}$ & $\begin{array}{c}\text { U.T.S. } \\
(\mathrm{MPa})\end{array}$ & $\begin{array}{c}\text { Reduction in } \\
\text { Area }(\%)\end{array}$ & $\begin{array}{c}\text { Elongation } \\
(\%)\end{array}$ \\
\hline As-received & R.T. & $1066( \pm 8)$ & $1311( \pm 16)$ & $26.2( \pm 2.8)$ & $15.5( \pm 1.4)$ \\
Heat treated & R.T. & $1117( \pm 9)$ & $1323( \pm 12)$ & $33.9( \pm 4.5)$ & $17.4( \pm 2)$ \\
\hline As-received & 650 & $913( \pm 11)$ & $1057( \pm 8)$ & $25.9( \pm 3.6)$ & $14.6( \pm 1.1)$ \\
Heat treated & 650 & $890( \pm 4)$ & $1026( \pm 5)$ & $31.3( \pm 0.8)$ & $17.9( \pm 0.7)$ \\
\hline
\end{tabular}

The values in parentheses represent 1 standard deviation from the mean.

The microhardness values for the material in the as-received and heat treated conditions are recorded in Table 3. A slight reduction in hardness has occurred in the heat treated material. 
Table 3 Microhardness measurements of IN-718

\begin{tabular}{ccc}
\hline Condition & HV & Standard Deviation \\
\hline As-received & 494 & 12 \\
Heat treated & 485 & 10 \\
\hline
\end{tabular}

Charpy impact toughness tests however revealed that the modified heat treatment had caused an increase in the absorbed energy although the difference is not as great as might be expected (Table 4). The amount of scatter in the results is also much lower in the heat treated material presumably due to the reduction in and more uniform distribution of the $\delta$-phase.

Table 4 Dynamic charpy impact test results (blunt notch)

\begin{tabular}{ccccc}
\hline Condition & $\begin{array}{c}\text { Total Test } \\
\text { Time }(\mathrm{m} \mathrm{sec})\end{array}$ & $\begin{array}{c}\text { Max Load } \\
(\mathrm{kN})\end{array}$ & $\begin{array}{c}\text { Absorbed } \\
\text { Energy at Max } \\
\text { Load }(\mathrm{J})\end{array}$ & $\begin{array}{c}\text { Total Absorbed } \\
\text { Energy }(\mathrm{J})\end{array}$ \\
\hline As-received & $0.77( \pm 0.04)$ & $15.4( \pm 0.4)$ & $7.0( \pm 1.8)$ & $19.4( \pm 0.4)$ \\
Heat treated & $0.94( \pm 0.08)$ & $17.1( \pm 0.3)$ & $9.5( \pm 0.1)$ & $22.9( \pm 0.1)$ \\
\hline
\end{tabular}

The value in parenthesis represent 1 standard deviation.

It might be expected that repeated use of this heat treatment could lead to excessive grain growth and, so to check this, samples of the material were cycled six times through the first step (see Table 1) of the heat treatment procedure. However no observable change in the grain size was noted.

To check the effectiveness of this rejuvenation method in practice, embrittled material, which had proven to be unrepairable, was processed through the modified heat treatment. Subsequent weld repairs were then carried out without any difficulty and no cracking was observed.

\section{Conclusions}

The most likely cause of the incipient embrittlement of an IN-718 diffuser case appeared to be excess $\delta$-phase formed as a result of repeated use of a weld repair heat treatment.

An alternative heat treatment was obtained from literature and this was shown to solution the $\delta$-phase and then re-precipitate it in controlled amounts. Improvements in ductility and toughness were noted. No deleterious effect on grain size, due to repeated use of the alternative process, was detected. Application of this process to an embrittled case enabled weld repairs to be done without further cracking.

This heat treatment procedure therefore offers a potential solution to the "ageing IN-718" problem and should extend life-times of existing components by reducing the high levels of the $\delta$-phase in a controlled and repeatable manner. 


\section{Acknowledgements}

The author wish to thank: Mr D Hope for performing the mechanical tests, Mr P Nkgomba for the metallographic preparation of the samples and Dr N R Comins for his support and useful comments.

\section{$\underline{\text { References }}$}

1. W. J. Mills, Welding Journal, Vol. 66, No. 4, April 1987, 113-5.

2. A. K. Koul, P. Au, N. Bellinger, R. Thamburaj, W. Wallace, J-P Immarigeon, Proc. Sixth Int'l Symposium on Superalloys, TMS, Seven Springs, PA, Sept. 18-22, 1988, 3.

3. G. R. Smolik, W. G. Reuter, Report ANCR-1227, Aerojet Nuclear Company, Idaho Falls, Idaho, 1975. 